\title{
Effect of Flavonoids on the Differentiation of 3T3-L1 Adipocytes
}

\author{
Keiko IwASHITA, ${ }^{1}$ Kohji YAMAKI ${ }^{2}$ and Tojiro TSUSHIDA ${ }^{2}$ \\ ${ }^{1}$ Institute of Applied Biochemistry, University of Tsukuba, 1-1-1 Tennodai, Tsukuba, Ibaraki 305-0006, Japan \\ ${ }^{2}$ National Food Research Institute, 2-1-12 Kannondai, Tsukuba, Ibaraki 305-8642, Japan
}

Received September 26, 2000; Accepted December 20, 2000

\begin{abstract}
The effect of dietary flavonoids (flavone, isoflavone, flavanone, chalcone, flavonol, and flavonol derivatives) on the differentiation of 3T3-L1 adipocytes was investigated. Glycerol-3-phosphate dehydrogenase (GPDH) activity, which is a hallmark of 3T3-L1 differentiation, was measured. The GPDH activity in the cells treated with quercetin, kaempferol, and isorhamnetin was significantly lower than that in the control cells. A low lipid accumulation in cells stained with Oil-Red $O$ was observed following treatment of these flavonols. The anti-differentiation action of quercetin was more potent than that of its derivatives. Quercetin directly inhibited the activity of GPDH extracted from mature 3T3$\mathrm{L1}$ adipocytes. The inhibitory action of quercetin on the differentiation of 3T3-L1 cells may involve the direct inhibition of GPDH, which is a key enzyme lipid synthesis.
\end{abstract}

Keywords : 3T3-L1 adipocyte, differentiation, flavonoid, glycerol-3-phospate dehydrogenase, lipid accumulation

Obesity can often trigger chronic diseases such as hypertension, cardiovascular disease, and diabetes mellitus (Scheen \& Luyckx, 1999; Rippe et al., 1998), thus making its prevention important for good human health. An imbalance between energy intake and expenditure results in obesity; extra energy is converted to lipids and pools in the adipocytes. Mature 3T3-L1 adipocytes secrete cytokines related to diseases such as a typeI plasminogen activator inhibitor (PAI-1) and TNF- $\alpha$ (Kawada, 1997). Adipocyte differentiation inhibitors are expected to be effective in the prevention of obesity, as suggested in a report on perilla oil (Okuno et al., 1997). 3T3-L1 fibroblasts established by Green and his colleagues from a mouse differentiate into adipocytes under suitable conditions (Green \& Kehinde, 1973; Green $\&$ Meuth, 1974). Lipids are accumulated during the process of differentiation, and the level of activity of glycerol-3-phosphate dehydrogenase, a key enzyme in lipogenesis, increases in the cells (Russell, 1981). Cultured 3T3-L1 adipocytes show many properties similar to those of normal adipocytes. Thus, this cell line is a convenient model system for research on adipocytes in vitro, and has been widely used for research related to obesity (Sul et al., 1998; Ohkura et al., 1995).

The physiological effects of flavonoids on culture cells have been demonstrated in many studies. Flavonoids, which are widely present in edible plants, are expected to provide physiological benefits for human health (Herrmann, 1976), and the effects of flavonoids on adipocytes have been reported. Quercitrin and apple polyphenols inhibited differentiation of 3T3-L1 adipocytes (Aida et al., 1999; Shoji et al., 2000). Procyanidin from grapes enhanced lipolysis in rat adipocytes (Ardevol et al., 2000). Our objective was to evaluate the flavonoids effective in the inhibition of lipogenesis-related enzymes in 3T3-L1 cell differentiation for obesity prevention.

E-mail moldive@nfri.affrc.go.jp

\section{Materials and Methods}

Chemicals Quercetin was obtained from Nacalai Tesque, Inc. (Kyoto), and quercitrin from Tokyo Chemical Industry Co., Ltd. (Tokyo). The other flavonoids used in this study, except for quercetin- and isorhamnetin-glucuronate, were obtained from Extrasynthese (Genay, France). Quercetin- and isorhamenetinglucuronate were synthesized as follows. One gram of $\mathrm{K}_{2} \mathrm{CO}_{3}$ and $5 \mathrm{~g}$ of acetobromoglucuronic acid methyl ester, were added to quercetin or isorhamenetin solution $(1 \mathrm{~g} / 20 \mathrm{ml}$ dimethyl sulfoxide) and left at room temperature for $2 \mathrm{~h}$. The mixture was poured into cold distilled water and precipitant was obtained by filtration. After washing with distilled water, the precipitant was dissolved in chloroform, evaporated and then freeze-dried. The solid was dissolved in $50 \mathrm{ml}$ of methanol and cooled at $5^{\circ} \mathrm{C}$. Then $1.5 \mathrm{ml}$ of natrium methylate was added to it and the mixture was left at $5^{\circ} \mathrm{C}$ for $30 \mathrm{~min}$ to remove acetyl ester. An equal volume of distilled water was added to it and the mixture was again left at room temperature for $30 \mathrm{~min}$ to hydrolyze the methyl ether. The mixture was then neutralized with $2 \mathrm{M} \mathrm{HCl}$, acidified with formic acid and then a precipitant was removed by filtration. The evaporated supernatant was fractionated for purification by Toyopearl HW40 column chromatography. The structure of synthesized flavonoid was confirmed from the mass spectrum, and the structure of the flavonoids used in this study are shown in Fig. 1.

Cell culture The 3T3-L1 preadipocyte cell line was obtained from the Health Science Research Resources Bank (Osaka). The cells were maintained in Dulbecco's Modified Eagle's Medium (DMEM) containing 10\% fetal bovine serum (FBS, ICN Biomedicals, Inc., Ohio). The medium was changed every two or three days. The cells were cultured in $60 \mathrm{~mm}$ diameter culture dishes at a density of $4 \times 10^{3}$ cells $/ \mathrm{ml}$. When the cells reached confluence after five or six days of incubation, the medium was changed for fresh medium containing $0.25 \mu \mathrm{M}$ dexamethasone and 0.5 mM 3-isobutyl-1-methyl-xanthine (DEX-MIX). The medium was again changed after DEX-MIX treatment for 
<smiles>[X]c1cc(-c2cc(=O)c3c(O)cc(O)cc3o2)ccc1O</smiles>

Apigenin: $\mathrm{X}=\mathrm{H}$

Luteolin: $\mathrm{X}=\mathrm{OH}$<smiles>[X]c1ccc(C2CC(=O)c3c(O)cc(O)cc3O2)cc1[X]</smiles>

Naringenin: $\mathrm{X}=\mathrm{H}, \mathrm{X}^{\prime}=\mathrm{OH}$

Hesperetin: $\mathrm{X}=\mathrm{OH}, \mathrm{X}^{\prime}=\mathrm{OCH}_{3}$<smiles>[X]c1cc(CCC(=O)c2c(O)cc(O)cc2O)ccc1O</smiles>

Phloretin: $X, \mathrm{R}=\mathrm{H}$

Phloridzin: $\mathrm{X}=\mathrm{H}, \mathrm{R}=$ glucose<smiles>[X]c1cc(-c2oc3cc(O)cc(O)c3c(=O)c2O)cc([X])c1O</smiles>

Kaempferol: $X, X^{\prime}=H$

Quercetin: $X=O H, X^{\prime}=H$

Myricetin: $X, X^{\prime}=O H$

Isorhamnetin: $\mathrm{X}=\mathrm{OCH}_{3}, \mathrm{X}^{\prime}=\mathrm{H}$

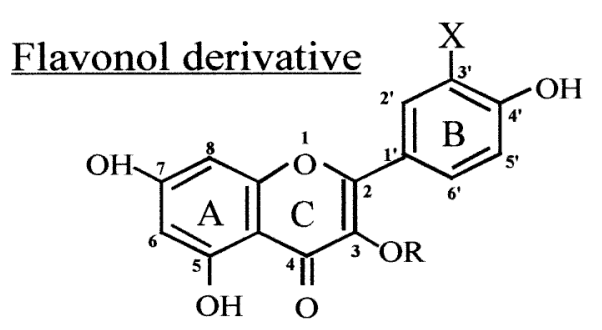

Quercitrin: $\mathrm{X}=\mathrm{OH}, \mathrm{R}=$ rhamnose Isoquercitrin: $\mathrm{X}=\mathrm{OH}, \mathrm{R}=$ glucose Quercetin-3-sulfate

: $\mathrm{X}=\mathrm{OH}, \mathrm{R}=$ sulfuric acid

Quercetin-3-glucuronate

: $\mathrm{X}=\mathrm{OH}, \mathrm{R}=$ glucuronic acid

Isorhamnetin-3-glucuronate

:X $=\mathrm{OCH}_{3}, \mathrm{R}=$ glucuronic acid

\section{Isoflavone}<smiles>[X]c1cc(O)cc2occ(-c3ccc(O)cc3)c(=O)c12</smiles>

Daidzein: $\mathrm{X}=\mathrm{H}$

Genistein: $\mathrm{X}=\mathrm{OH}$

Fig. 1. Structures of flavonoids used in this study.

$48 \mathrm{~h}$, and insulin (final concentration $1 \mu \mathrm{g} / \mathrm{ml}$ ) and flavonoids, dissolved in dimethyl sulfoxide, were added. The flavonoid and insulin were added to the medium at the time of every medium change during seven days of incubation.

Glycerol-3-phosphate dehydrogenase (GPDH) activity and triglyceride (TG) content The 3T3-L1 cells were harvested by Hayashi's method with some modification (Hayashi et al., 1981). After removing the medium, the cells were washed twice with 5 $\mathrm{ml}$ of PBS. The cells were collected in $1 \mathrm{ml}$ of cold sonication buffer (pH $7.525 \mathrm{~mm}$ tris buffer containing $1 \mathrm{mM}$ EDTA) using a cell scraper, and then sonicated. Two hundred microliters of the suspension was used to measure the TG concentration. The TG concentration in the cells was measured using E-test WAKO (WAKO Pure Chemical Industries Ltd., Osaka). The remaining portion of the suspension was centrifuged at $8000 \times g$ for $20 \mathrm{~min}$ at $4^{\circ} \mathrm{C}$, and the supernatant was stored at $-80^{\circ} \mathrm{C}$ until used in the GPDH activity assay. This assay was carried out by measuring the decrease in absorbance of NADH at $340 \mathrm{~nm}\left(25^{\circ} \mathrm{C}\right)$ and the amount of activity per $\mathrm{mg}$ of protein was calculated. The protein concentration was determined using the DC-protein assay system (BIO-RAD Japan, Tokyo). The GPDH activity and the TG concentration per $\mathrm{mg}$ of protein in 3T3-L1 cells were each expressed as the ratio (\%) to the control value. For observation of lipids in the cells, Oil-Red O staining was performed by the method described Kuri-Harcuch and Green (1978). The direct effect on the GPDH activity was measured with GPDH extracted from matured 3T3-L1 adipocytes. A decrease in absorbance at $340 \mathrm{~nm}$ was measured at each concentration of flavonoid.

Lipolysis The method of Sakuramata and Kusano (1998) was used for the lipolysis measurement with a slight modifica- 
tion. The sample solution was added to a cultured medium of mature adipocytes in a $60 \mathrm{~mm}$ diameter dish. The glycerol released into the medium from mature 3T3-L1 adipocytes after incubation for $24 \mathrm{~h}$ was measured by F-kit Glycerol (Boehringer Mannheim, Tokyo), and the free fatty acids released into the medium were measured by a NEFA C-Test WAKO (WAKO Pure Chemical Industries, Ltd.).

\section{Results}

Measurements of the GPDH activity in the 3T3-L1 cells treated with 50 and $100 \mu \mathrm{M}$ aglycones were shown in Fig. 2A. Microscope observations indicated that treatment of these aglycones with over $200 \mu \mathrm{M}$ damaged the cells. The GPDH activity in the cells treated with quercetin, kaempferol, and isorhamnetin, which belong to the flavonol group, was lower than in the untreated group $\left({ }^{* *} p<0.01\right)$, and these effects were dose-dependent. However, GPDH activity in the 3T3-L1 cells was not affected by treatment with myricetin, which belongs to the fla-
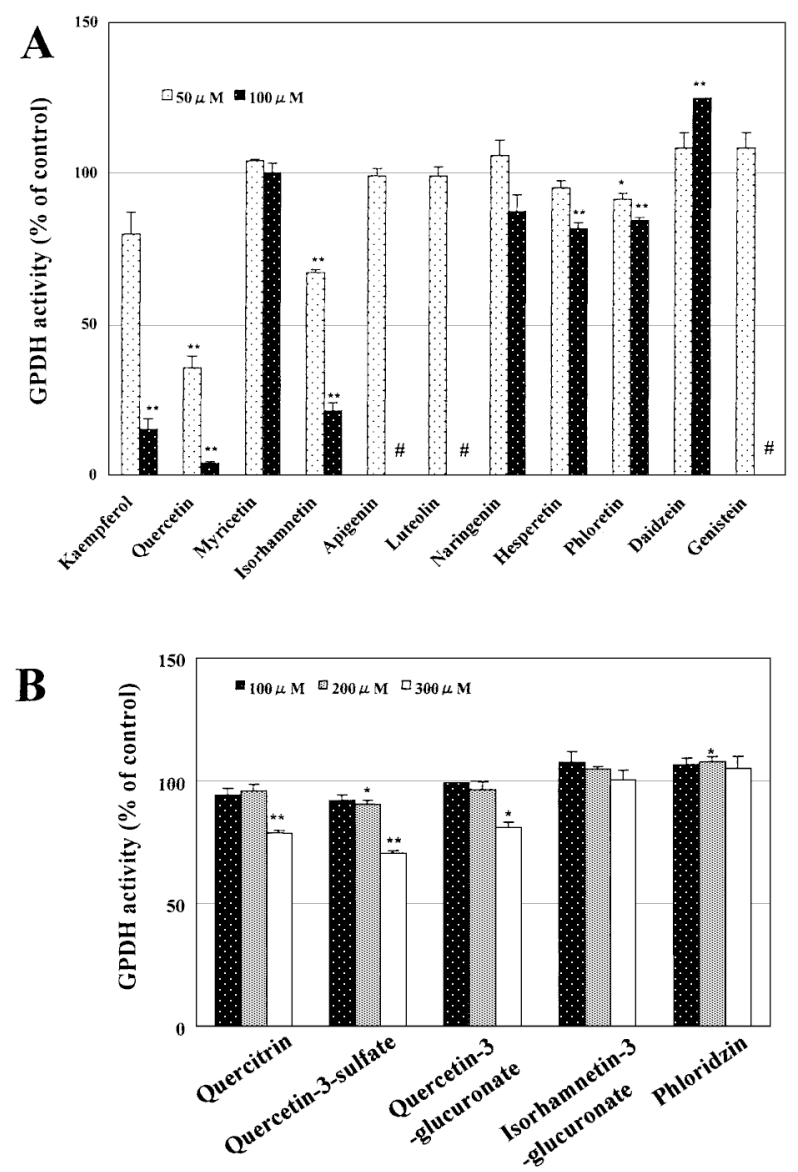

Fig. 2. Glycerol-3-phosphate dehydrogenase (GPDH) activity in the 3T3L1 cells treated with flavonoids. A: Effect of aglycones on the GPDH activity in 3T3-L1 cells. After seven days of incubation, the GPDH activity was measured as an indicator of 3T3-L1 cell differentiation. Results are shown as the ratio of the control and are expressed as means $\pm \mathrm{SE}, n=3$. Asterisk indicates a significant difference $\left({ }^{*} p<0.05,{ }^{* *} p<0.01\right)$ compared to the control, as determined by Student's $t$-test. \#: The GPDH activity of 3T3-L1 cells treated with $100 \mu \mathrm{M}$ apigenin, luteolin, and genistein was not measured because these treatments damaged the cells. B: Effect of flavonol derivatives and phloridzin on the GPDH activity in the 3T3-L1 cells. Results are shown as the ratio of the control and are expressed as means $\pm \mathrm{SE}, n=3$. Asterisk indicates a significant difference $\left({ }^{*} p<0.05,{ }^{* *} p<0.01\right)$ compared to the control as determined by Student's $t$-test. quercitrin: quercetin-3-rhamnoside. vonol group. The GPDH activity in the cells was not affected by treatment with either $50 \mu \mathrm{M}$ apigenin or luteolin, which belong to the flavone group. Because the $100 \mu \mathrm{M}$ apigenin or luteolin treatments damaged the cells (\#), the GPDH activity in the cells could not be measured. The GPDH activity in the cells treated with naringenin and hesperetin, which belong to the flavanone group, was lower than the control level, and these effects were also dose-dependent. The treatment with $100 \mu \mathrm{M}$ hesperetin was significant $\left(^{* *} p<0.01\right)$, however the suppressive effect was lower than the effect of the flavonols. The GPDH activity in the cells treated with phloretin was lower than the control $\left(^{*} p<0.05\right.$, ${ }^{* * *} p<0.01$ ), but the suppressive effect was lower than the effect of the flavonols. Daidzein and genistein belong to the isoflavone group. The GPDH activity was enhanced by $100 \mu \mathrm{M}$ daidzein treatment $\left.{ }^{* *} p<0.01\right)$. In contrast, the effect of a $50 \mu \mathrm{M}$ genistein treatment was not significant, and the GPDH activity was not measured because the $100 \mu \mathrm{M}$ genistein treatment damaged the cells(\#).

These results suggest that the GPDH activity of 3T3-L1 cells was suppressed by the treatments with phloretin and flavonol, but not those with myricetin. The GPDH activity in the cells treated with phloridzin and the derivatives (glucoside, glucuronate, and sulfate) of flavonol was then investigated (Fig. 2B), and it was found not to be affected by $100 \mu \mathrm{M}$ treatments with these derivatives. Nor were the cells damaged by $300 \mu \mathrm{M}$ treatment with these derivatives. Isoquercitrin, quercetin-3-glucoside, damaged the cells at $50 \mu \mathrm{M}$, but did not affect the GPDH activity at $10 \mu \mathrm{M}$ (data not shown). The GPDH activity was significantly lower than that in the control cells following $300 \mu \mathrm{M}$ treatment with quercitrin (quercetin-3-rhamnoside), quercetin-3-sulfate, and quercetin-3-glucuronic acid $\left({ }^{*} p<0.05,{ }^{* *} p<0.01\right)$. The GPDH suppressive effect by the derivatives was only observed at a high concentration and was lower than the effect of the flavonol aglycone. The cells were treated with quercetin, kaempferol, and isorhamnetin and stained with Oil-Red O. The lipids in the adipocytes stained a red color. A low lipid content was observed following the treatment of these flavonols, as shown in Fig. 3A. Oil droplets in the adipocytes treated with $50 \mu \mathrm{M}$ of the flavonols were revealed under light microscopic observation (Fig. 3B). The low lipid content was determined by measuring the TG concentration (Table 1). The GPDH activity and TG content at $50 \mu \mathrm{M}$ of quercetin were the lowest in the cells of all tested flavonoids in this study. We therefore concluded that quercetin has the most potent anti-differentiation effect of all the tested flavonoids. The lipolysis effect of quercetin was measured (Fig. 4), but no free fatty acid release was observed following the quercetin treatment. Glycerol release by the $100 \mu \mathrm{M}$ quercetin addition was observed, but was weak compared with the data of isoproterenol

Table 1. Effect of quercetin, isorhamnetin and kaempferol on the differentiation of 3T3-L1 cells.

\begin{tabular}{lcc}
\hline \multicolumn{1}{c}{ Sample } & GPDH activity $(\%$ of control) & TG $(\%$ of control $)$ \\
\hline Control & $100.0 \pm 4.63$ & $100.0 \pm 0.61$ \\
Kaempferol & $79.8 \pm 4.23^{a)}$ & $68.6 \pm 4.21^{a)}$ \\
Isorhamnetin & $67.0 \pm 1.05^{a)}$ & $69.8 \pm 1.81^{a)}$ \\
Quercetin & $35.5 \pm 4.02^{a b}$ & $50.6 \pm 1.14^{a b)}$ \\
\hline
\end{tabular}

The concentration of sample was $50 \mu \mathrm{M}$. Values are means $\pm \operatorname{SE}(n=3)$. ${ }^{a)} p<0.01$ vs. control, ${ }^{b)} p<0.01$ vs. quercetin 
treatment as the positive control $\left({ }^{* *} p<0.01\right)$.

The GPDH inhibitor may suppress adipocyte differentiation. Aida et al. (1999) reported that quercitrin suppressed the GPDH activity and inhibited 3T3-L1 differentiation. The direct effect on GPDH activity by quercetin, kaempferol, and isorhamnetin was measured (Fig. 5). Directly added kaempferol and isorhamnetin
A
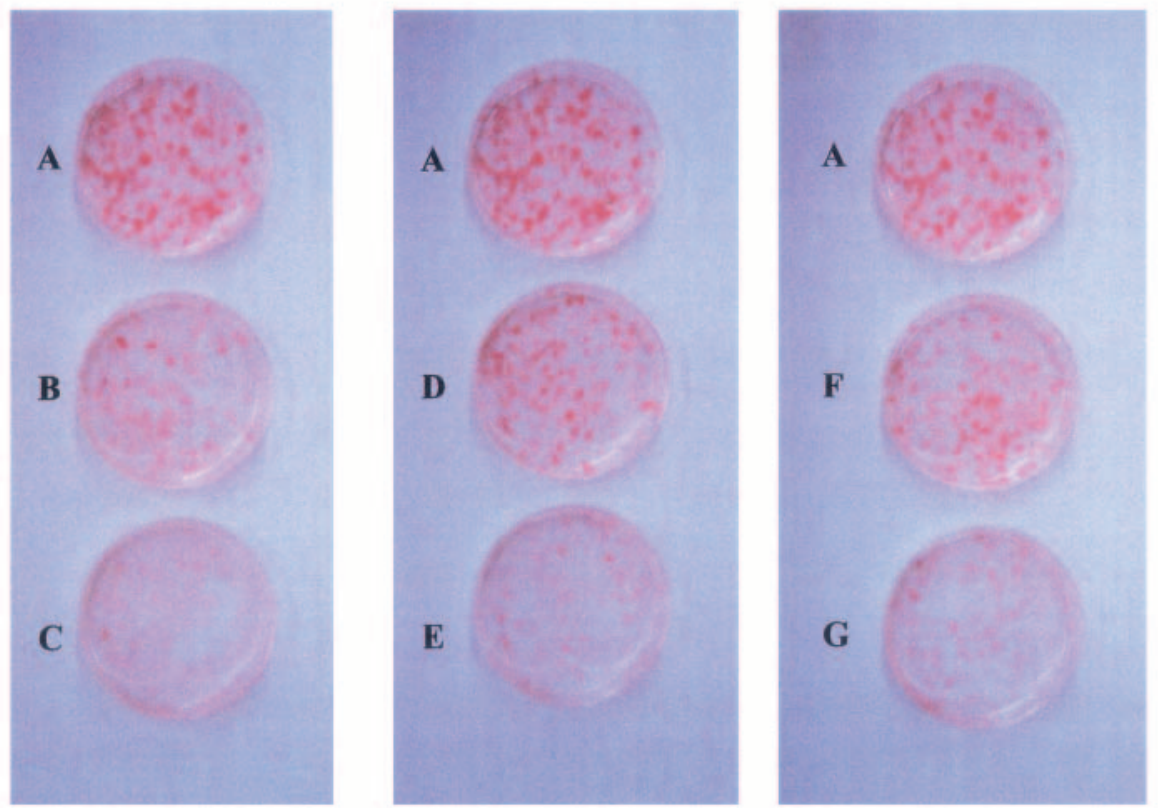

B
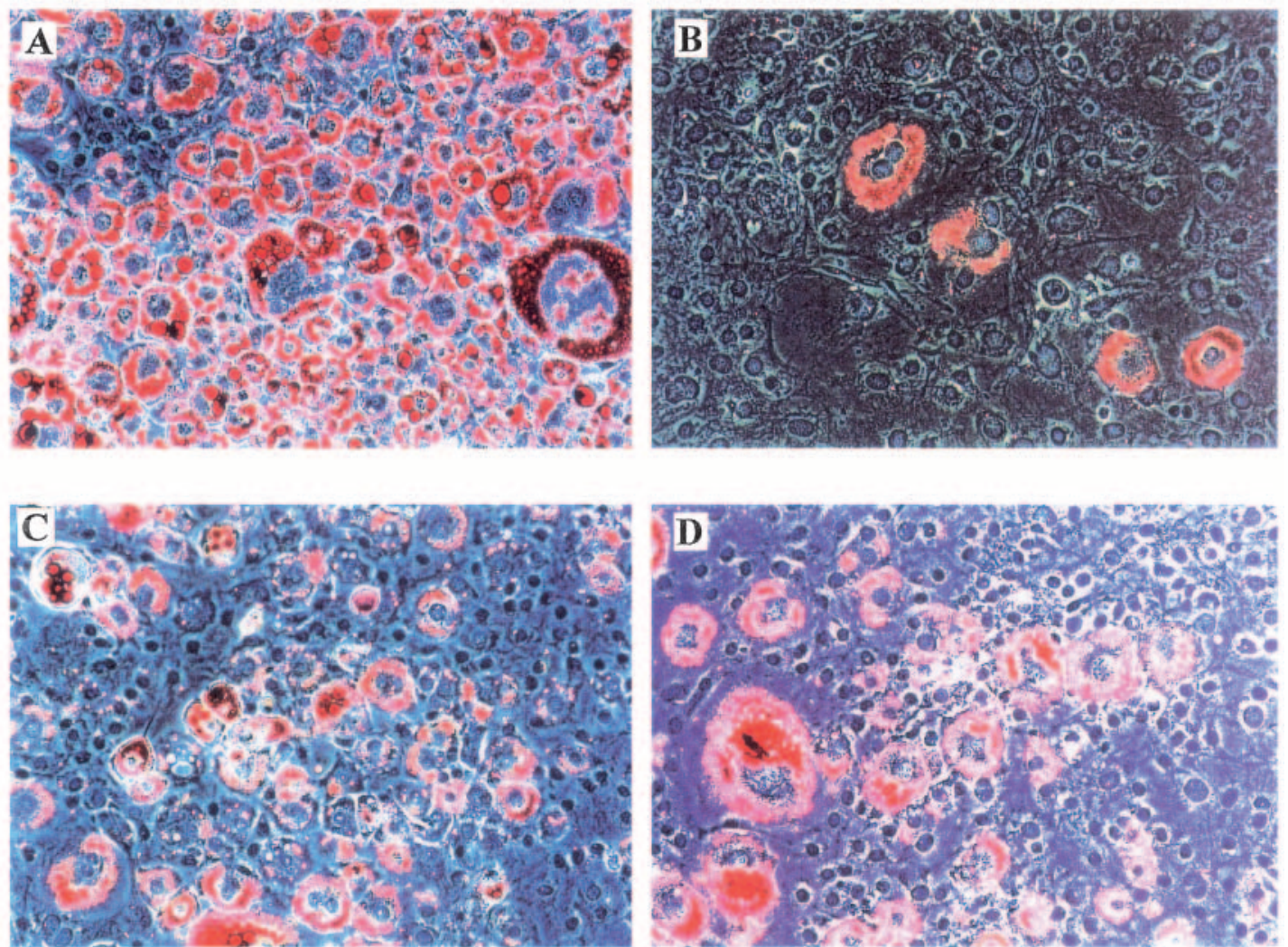

Fig. 3. Effects of flavonols on the lipid accumulation in 3T3-L1 cells. A: The cells were fixed in 10\% formaldehyde and stained with Oil-Red O after seven days of treatment. The intensity of the Oil-Red $\mathrm{O}$ staining is indicative of the relative lipid content. The cell-orienting effect of the flavonoids is evident. A) control, B) $50 \mu \mathrm{M}$ quercetin, C) $100 \mu \mathrm{M}$ quercetin, D) $50 \mu \mathrm{M}$ isorhamnetin, E) $100 \mu \mathrm{M}$ isorhamnetin, F) $50 \mu \mathrm{M}$ kaempferol, G) $100 \mu \mathrm{m}$ kaempferol. B: Microscope observations of Oil-Red O-stained 3T3-L1 cells treated with $50 \mu \mathrm{m}$ quercetin, isorhamnetin and kaempferol ( $\times 160$ magnification). The lipid droplets were stained by Oil-Red $\mathrm{O}$ and colored red. A) control, B) quercetin treatment, C) isorhamnetin treatment, D) kaempferol treatment. 

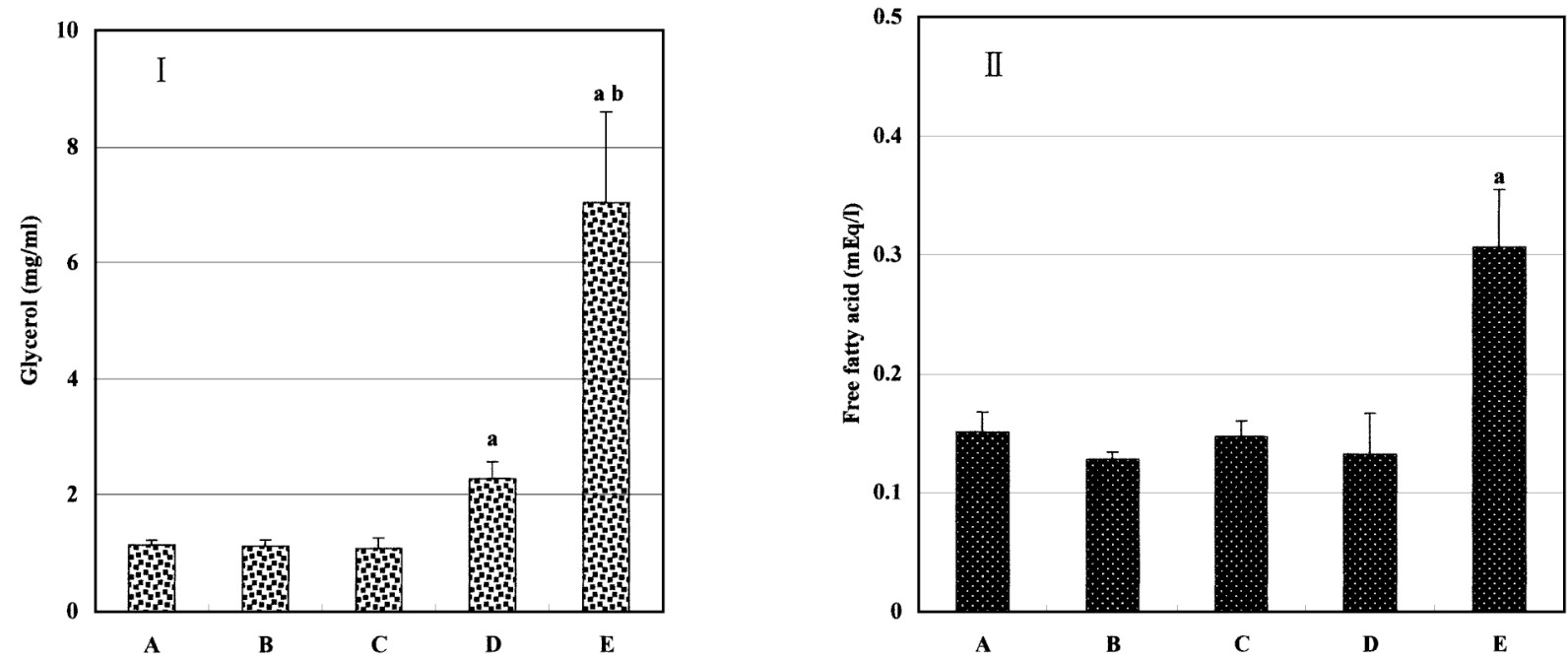

Fig. 4. Effects of quercetin on the release of glycerol and free fatty acid from mature 3T3-L1 cells into the culture medium for $24 \mathrm{~h}$. I, Glycerol release; II Free fatty acid release. The results are expressed as means \pm SE, $n=3$. (a) $p<0.01$, significantly different from control cells. (b) $p<0.01$, significantly different from quercetin treated cells. A) control, B) quercetin $10 \mu \mathrm{M}$, C) quercetin $50 \mu \mathrm{M}$, D) quercetin $100 \mu \mathrm{M}$, E) isoproterenol $10^{-6} \mathrm{M}$.
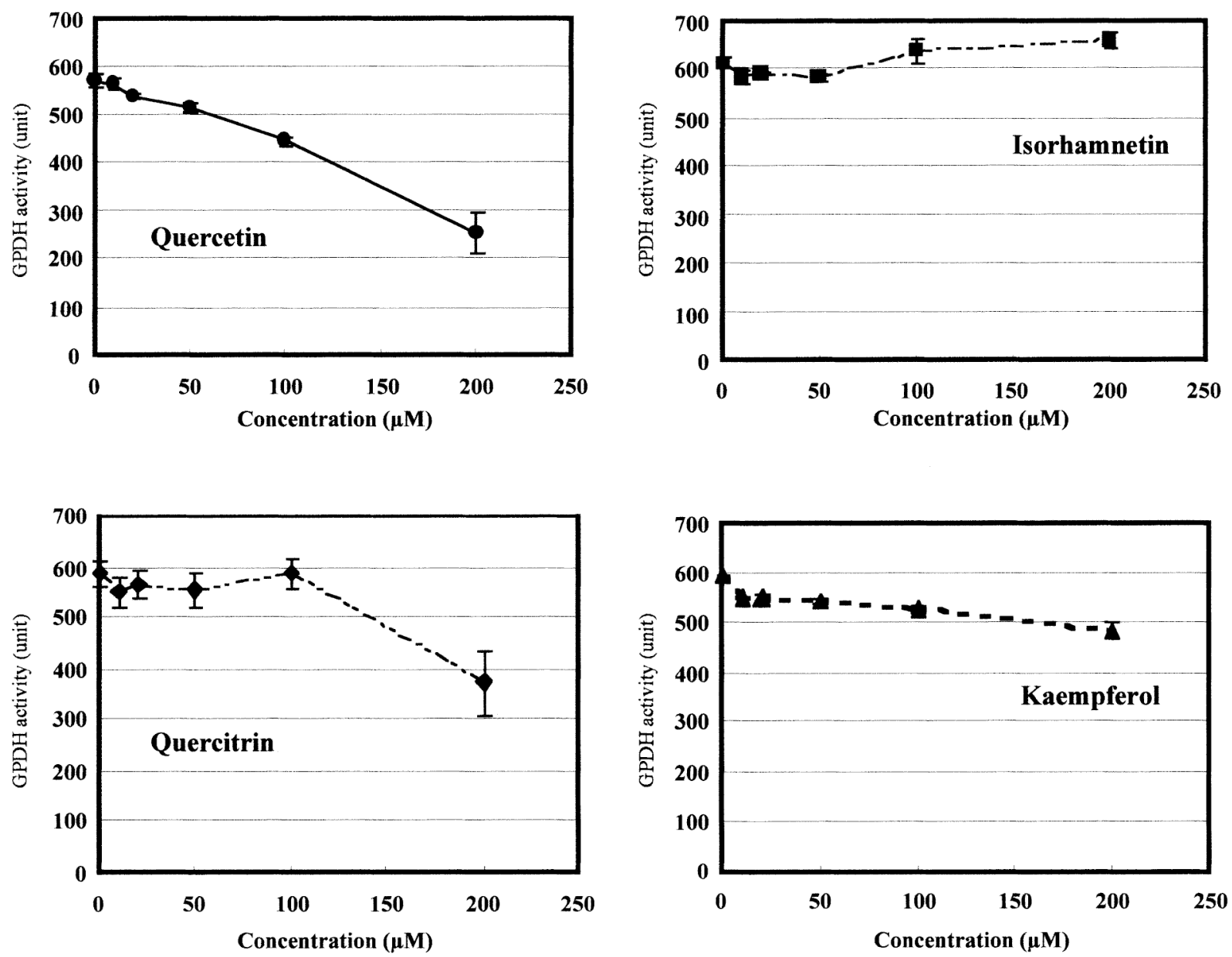

Fig. 5. Direct effect of quercetin, isorhamnetin, kaempferol, and quercitrin on the activity of GPDH from mature 3T3-L1 cells.

affected the GPDH activity very little, while quercetin inhibited the activity in a dose-dependent manner. The inhibitory activity of quercetin was shown to be stronger than that of quercitrin; the
GPDH activities were lower following quercetin additions at each concentration than they were following quercitrin addition. 


\section{Discussion}

We examined the effects of flavonoid, shown in Fig.1, on the GPDH activity, which is a hallmark of 3T3-L1 adipocyte differentiation. Daidzein enhanced GPDH activity in the cells in this study, supporting Sekiya's report (Sekiya 1999). The flavonol aglycones showed inhibition of GPDH in the cells and the inhibition was stronger than its glucoside, glucuronate and sulfate. The treatment of $100 \mu \mathrm{M}$ hesperetin was significant $\left({ }^{* *} p<0.01\right)$ and the suppressive effect was lower than the effect of the flavonols. Hesperidin, hesperetin 7-rhamnoglycoside, was not effective on the GPDH at $100 \mu \mathrm{M}$ (data not shown). The GPDH activity in the cells treated with 50 and $100 \mu \mathrm{M}$ of phloretin was lower than the control $\left(" p<0.05,{ }^{* *} p<0.01\right)$; one hundred micromoles of phloridzin showed a minimally suppressive effect. This activity was significantly inhibited by treatment with quercetin, kaempferol, and isorhamnetin, which belong to the flavonol group $\left({ }^{* *} p<0.01\right)$. These flavonols inhibited lipid accumulation in the 3T3-L1 cells. These results indicate that flavonol, quercetin, kaempferol, and isorhamnetin, affect the anti-differentiation of 3T3-L1 adipocytes. The potential order of the anti-differentiation action was quercetin $>$ kaempferol $\fallingdotseq$ isorhamnetin. The inhibitory effect was revealed at a lower concentration of flavonol aglycone than of the flavonol derivatives. The flavonol structure, hydroxyl group of the 3-position of the C-ring, appears to be important for anti-differentiation action.

Flavonoids exist mainly in glycoside form in plants. The metabolism of flavonoids in vivo, which are via deglycosylation, glucuronation, sulfate conjugation, and methylation, is not completely understood, but some investigations have been reported. Flavonoid glycosides were deglycosylated by bacteria in the large intestine (Tamura et al., 1980) and by $\beta$-glucosidase in the small intestine and liver (Day et al., 1998; Ioku et al., 1998). Some flavonoids in the circulation are changed to glucuronate or sulfate in the liver (Terao, 2000). Some parts of quercetin are thought to be changed to isorhamnetin by methylation in vivo. There is a possibility that flavonoid glycoside, aglycone, its glucuronate, and sulfate are absorbed in the small intestine (Tsushida, 1998). In this study, the anti-differentiation activity of quercetin and isorhamentin on 3T3-L1 cells was more potent than its glycoside in vitro. After deglycosylation by the enzymes, quercetin and isorhamnetin, an aglycone form, may be more effective in the anti-differentiation of adipocytes than its glycoside, in vivo.

It is possible that both lipogenesis and lipolysis occur in the adipocytes. It is assumed that the quercetin suppresses fat synthesis or enhances lipolysis in adipocytes. We performed experiments examining release of glycerol and fatty acid from mature 3T3-L1 adipocytes to investigate the lipolysis action of quercetin. However, when mature 3T3-L1 adipocytes were treated with quercetin, very little glycerol and fatty acid release, which is indicative of lipolysis, was observed. The inhibition of fat accumulation in 3T3-L1 cells by quercetin is suggested to result in anti-differentiation and not lipolysis.

Some mechanisms of anti-differentiation on 3T3-L1 cells are assumed. Insulin action on glucose uptake is an important factor in adipocyte differentiation. Glucose uptake inhibition is thought to be important in the anti-differentiation of adipocytes. Flavonoids were reported as potential glucose uptake inhibitors in U937 cells and Jurkat cells (Park, 1999). The effective order of flavonoids on glucose uptake inhibition in U937 cells did not correspond to the anti-differentiation activity of 3T3-L1 cells by flavonoids. GPDH activity in the 3T3-L1 cells was not suppressed by treatment with myricetin, which belongs to the flavonol group. Myricetin has insulinomimetic effects on lipogenesis in rat adipocytes (Ong \& Khoo, 1996). It was suggested that the differentiation of 3T3-L1 was not inhibited because of an insulin-like action by myricetin. Phloretin and phloridzin are known as glucose transport inhibitors; the anti-differentiation effect of phloretin may involve glucose transport inhibition, while phloridzin did not disturb the 3T3-L1 differentiation. The anti-differentiation effect by flavonoid was thought to be not only via glucose transport inhibition. Wortmanin, a PI-3 kinase inhibitor, inhibits the differentiation of adipocytes (Tomiyama et al., 1995). Protein kinase C (PKC) is involved in regulating glucose transport stimulated by insulin in rat adipocytes (Christensen $e t$ al., 1987). Quercetin selectively inhibits the insulin receptor function in vitro and the bioresponses of insulin and insulinomimetic agents in rat adipocytes (Shisheva \& Shechter, 1992). The relationship between the flavonoid structure and the inhibition of PI-3 kinase was compared with PKC inhibition (Agullo et al., 1997). Some flavonol and flavone were PKC inhibitors and also PI3 kinase inhibitors. Myricetin was the most potent PI-3 kinase inhibitor among flavonols. However, no anti-differentiation activity due to flavone or myricetin was observed in this study. It is assumed that anti-differentiation by quercetin involves other actions, not only inhibition of these kinases and glucose uptake.

A GPDH inhibitor may suppress the lipid synthesis. Anacardic acids from Ginkgo inhibit GPDH and lipid synthesis of bacteria and yeast (Murata et al., 1997). Quercitrin suppressed the GPDH activity and inhibited 3T3-L1 differentiation at 100 $\mu \mathrm{g} / \mathrm{ml}(\fallingdotseq 300 \mu \mathrm{M})$ (Aida et al., 1999). The GPDH inhibition by quercetin was stronger than that by quercitrin. The concentration at which quercetin inhibited 3T3-L1 differentiation $(50 \mu \mathrm{M})$ was lower than the concentration necessary for inhibition by quercitrin $(\fallingdotseq 300 \mu \mathrm{M})$. Details of the mechanism responsible for the effect of the flavonol remain unclear. The mechanism of anti-differentiation by quercetin is thought to involve the direct inhibition of GPDH.

Flavonoids, especially those with quercetin, are widespread in edible plants. A vegetable rich meal is low in calories and is a high vitamin source. Flavonoids in vegetables are believed to help in preventing obesity.

Acknowledgement The encouragement and support of Professor E. Munekata at the Institute of Applied Biochemistry, University of Tsukuba are greatly appreciated.

\section{References}

Agullo, G., Gamet-Payrastre, L., Manenti, S., Viala, C., Remesy, C., Chap, H. and Payrastre, B. (1997). Relationship between flavonoid structure and inhibition of phosphatidylinositol 3-kinase: a comparison with tyrosine kinase and protein kinase $\mathrm{C}$ inhibition. Biochem. Pharm., 53, 1649-1657.

Aida, K., Wada, T., Uchino, K. and Tsushida, T. (1999). Glycerol-3phosphate dehydrogenease inhibitor (2) Inhibitory effect of lipid accumulation of quercitrin. 119 th meeting of the Pharmaceutical Society of Japan, Tokushima, March 31, p. 154.

Ardevol, A., Blade, C., Salvado, M.J. and Arola, L. (2000). Changes in lipolysis and hormone-sensitive lipase expression caused by procyanidins in 3T3-L1 adipocytes. Int. J. Obes., 24, 319-324.

Christensen, R.L., Shade, D.L., Graves, C.B. and McDonald, J.M. 
(1987). Evidence that protein kinase $C$ is involved in regulating glucose transport in the adipocyte. Int. J. Biochem., 19, 259-265.

Day, A.J., DuPont, M.S., Ridley, S., Rhodes, M., Rhodes, M.J.C., Morgan, M.R.A. and Williamson, G. (1998). Deglycosylation of flavonoid and isoflavonoid glycosides by human small intestine and liver $\beta$-glucosidase activity. FEBS Lett., 436, 71-75.

Green, H. and Kehinde, O. (1973). Sublines of mouse 3T3 cells that accumulate lipid. Cell, 1, 113-116.

Green, H. and Meuth, M. (1974). An established pre-adipose cell line and its differentiation in culture. Cell, 3, 127-133.

Hayashi, I., Nixon, T., Morikawa, M. and Green, H. (1981). Adipogenic and anti-adipogenic factors in the pituitary and other organs. Proc. Natl. Acad. Sci. USA, 78, 3969-3972.

Herrmann, K. (1976). Flavonols and flavones in food plants: a review J. Food. Technol., 11, 433-438.

Ioku, K., Pongpiriyadacha, Y., Konishi, Y., Takei, Y., Nakatani, N. and Terao, J. (1998). $\beta$-Glucosidase activity in the rat small intestine toward quercetin monoglucosides. Biosci. Biotechnol. Biochem., 62, $1428-1431$.

Kawada, T. (1997). Adipocyte differentiation and its specific functions. Saishin Igaku, 52, 1078-1086 (in Japanese).

Kuri-Harcuch, W. and Green, H. (1978). Adipose conversion of 3T3 cells depends on a serum factor. Proc. Natl. Acad. Sci. USA, 75, 6107-6109.

Murata, M., Irie, J. and Homma, S. (1997). Inhibition of lipid synthesis of bacteria, yeast and animal cells by anacardic acids, glycerol3-phosphate dehydrogenase inhibitors from Ginkgo. Lebensm. Wiss. U. Technol., 30, 458-463.

Ohkura, K., Mori, M., Terada, H. and Makino, S. (1995). Stimulation of insulin action and stabilization of cell membrane in 3T3-L1 cells by glycinin acidic subunit $\mathrm{A}_{1 \mathrm{a}}$. Biosci. Biotechnol. Biochem., 59, $1485-1488$.

Okuno, M., Kajiwara, K., Imai, S., Kobayashi, T., Honma, N., Maki, T., Suruga, K., Goda, T., Takase, S., Muto, Y. and Moriwaki, H. (1997). Perilla oil prevents the excessive growth of visceral adipose tissue in rats by down-regulating adipocyte differentiation. J. Nutr., 127, 1752-1757.

Ong, K.C. and Khoo, H.E. (1996). Insulinomimetic effects of myricetin on lipogenesis and glucose transport in rat adipocytes but not glucose transport translocation. Biochem. Pharm., 51, 423-429.

Park, J.B. (1999). Flavonoids are potential inhibitors of glucose uptake in U937 cells. Biochem. Biophys. Res. Comm., 260, 568-574.

Rippe, J.M., Crossley, S. and Ringer, R. (1998). Obesity as a chronic disease: modern medical and lifestyle management. J. Am. Diet Assoc., 98, S9-15.

Russell, T.R. (1981). Growth and cytodifferentiation of 3T3-L1 preadipocytes into adipocytes. Methods Enzymol., 72, 720-723.

Sakuramata, Y and Kusano, S. (1998). Screening of plant extracts with potential to stimulate lipolysis in 3T3-L1 cells. J. Jpn. Soc. Nutr. Food Sci. 51, 361-364.

Scheen, A.J. and Luyckx, F.H. (1999). Medical aspects of obesity. Acta. Chir. Belg., 99, 135-139.

Sekiya, K. (1999). Physiological function of beans. Nogyo oyobi Engei, 74, 108-112 (in Japanese).

Shisheva, A. and Shechter, Y. (1992). Quercetin selectively inhibits insulin receptor function in vitro and the bioresponses of insulin and insulinomimetic agents in rat adipocytes. Biochemistry, 31, 80598063.

Shoji, T., Kobori, M., Shinmoto, H., Yanagida, A., Kanda, T. and Tsushida, T. (2000). Inhibitory effects of apple polyphenols on differentiation of 3T3-L1 cells into adipocytes. Food Sci. Technol. Res., 6, 119-121.

Sul, H., Smas, C., Wang, D. and Li, C. (1998). Regulation of fat synthesis and adipose differentiation. Prog. Nucleic Acid Res. Mol. Biol., 60, 317-345.

Tamura, G., Gold, C., Ferro-Luzzi, A. and Ames, B. N. (1980). Fecalase: a model for activation of dietary glycosides to mutagens by intestinal flora. Proc. Natl. Acad. Sci. USA, 77, 4961-4965.

Terao, J. (2000). Prevention of oxidation stress by antioxidants in food. Symposium of the Japan Society for Bioscience, Biotechnology, and Agrochemistry 2000, Tokyo, April 1-2, p476.

Tomiyama, K., Nakata, H., Sasa, H., Arimura, S., Nishio, E. and Watanabe, Y. (1995). Wortmanin, a specific phosphatidylinositol 3-kinase inhibitor, inhibits adipocytic differentiation of 3T3-L1 cells. Biochem. Biophys. Res. Comm., 212, 263-269.

Tsushida, T. (1998). Flavonoid metabolism. In "Medical Science of Flavonoid," ed by T. Yoshikawa. Kodansha Scientific. Tokyo. pp. $18-23$. 